\title{
KAJIAN ELEMEN VISUAL PADA FOTO PROMOSI PRODUK FASHION LOKAL 'COTTON INK’ DI INSTAGRAM
}

\author{
Ekariana Fitrina Irawan ${ }^{1}$, Naomi Haswanto ${ }^{2}$,Dianing Ratri ${ }^{3}$ \\ Magister Desain, Fakultas Seni Rupa dan Desain, Institut Teknologi Bandung \\ Email: ekarianafirawan@gmail.com
}

\begin{abstract}
Abstrak
Ketatnya persaingan bisnis fashion di Indonesia, membuat tidak semua merek produk fashion lokal dapat diterima ataupun bertahan di tengah masyarakat. 'Cotton Ink' merupakan salah satu merek produk fashion lokal yang mampu bersaing dan menjadi populer. Studi dokumentasi menyebutkan bahwa Instagram menjadi media promosi online yang paling efektif dalam proses pemasaran 'Cotton Ink', serta mampu meningkatkan penjualan produk. Penelitian ini bertujuan untuk mengkaji visual foto 'Cotton Ink' di media sosial Instagram dilihat dari elemen visual fotografi. Metode penelitian dilakukan secara deskriptif kualitatif dengan analisis konten. Teknik pengumpulan data dilakukan dengan cara observasi, focus group discussion, studi dokumentasi visual foto Instagram, dan studi pustaka. Data dianalisis dengan analisis visual dan menggunakan pendekatan teori umum tentang fotografi serta gaya busana. Dari hasil penelitian diketahui bahwa visual foto 'Cotton Ink' di media sosial Instagram telah memenuhi elemen visual fotografi, serta mendapat respon yang positif dari konsumen. Adapun elemen visual fotografi yang dikaji tersebut diantaranya meliputi tonal warna, jenis pengambilan gambar, arah pandang kamera, objek foto, latar, komposisi, aksesoris dan milineris, serta atribut busana. Dengan memanfaatkan elemen visual fotografi pada setiap unggahan foto, membuat konsumen memiliki ketertarikan visual serta menumbuhkan minat beli terhadap produk. Hal tersebut menunjukkan bahwa penggunaan elemen visual fotografi dalam setiap unggahan foto di media promosi online Instagram dapat dimanfaatkan sebagai salah satu upaya untuk memperkuat strategi pemasaran digital produk fashion di era rovolusi industri 4.0 saat ini.
\end{abstract}

Kata kunci: produk fashion, elemen visual, Instagram.

\begin{abstract}
The tightness of fashion business competition in Indonesia, has made not all local fashion brands acceptable or survives in the market. 'Cotton Ink' in one of the local fashion brands that is able to compete and became popular. The documentation study states that Instagram is the most effective online promotional media in the 'Cotton Ink's marketing process, and is able to increase product sales. This study aims to examine the visual photos of 'Cotton Ink' on Instagram in terms of the visual elements of photography. The research was conducted using qualitative descriptive methods and content analysis. Data collection techniques were carried out by observation, focus group discussions, visual documentation studies of Instagram photos, and literature studies. Data were analyzed using visual analysis and using a general theoretical approach to photography and fashion. From the research results, it is known that the visual photos of 'Cotton Ink' on Instagram has fulfilled the visual elements of photography, and it has received a positive response from consumers. The visual elements of photography studied include color tonal, type of image, direction of camera view, photo object, background, composition, accessories, and clothing attributes. By utilizing the visual elements of photography in every photo upload, it makes consumers have visual interest and fosters purchase intention for the product. This shows that the use of photographic visual elements in every photo upload on Instagram can be used as an effort to strengthen the digital marketing strategy of fashion products in the era of industrial revolution 4.0. currently.
\end{abstract}

Keywords: fashion product, visual elements, Instagram.

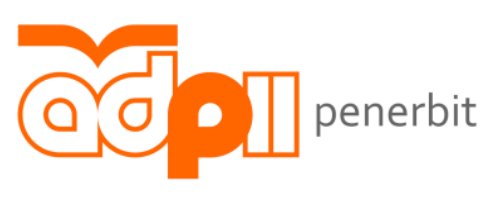

Penerbit Aliansi Desainer Produk Industri Indonesia 


\section{Pendahuluan}

Seiring dengan perkembangan teknologi digital, saat ini belanja online sudah menjadi gaya hidup baru masyarakat Indonesia. Hal tersebut juga memunculkan inovasi baru dalam dunia pemasaran, yakni dikenal dengan istilah social media marketing. Social media marketing merupakan bentuk pemasaran yang menggunakan media sosial untuk memasarkan suatu produk, jasa, brand atau isu dengan memanfaatkan khalayak yang berpartisipasi di media sosial tersebut [1]. Menurut hasil riset yang dilakukan oleh platform manajemen media sosial 'Hootsuite' dan agensi social marketing 'We Are Social' berjudul "Global Digital Reports 2020", menunjukkan bahwa Indonesia menduduki peringkat keempat sebagai negara terbesar yang menggunakan media sosial Instagram [2]. Selain itu, menurut data penelitian yang dilakukan oleh 'NapoleonCat', salah satu perusahaan analisis Social Media Marketing yang berbasis di Warsawa Polandia, menyebutkan bahwa pengguna Instagram didominasi oleh golongan usia produktif pada rentang 18-34 tahun atau yang dikenal dengan sebutan generasi milenial, sementara jika dilihat dari segi gender, didominasi oleh kategori wanita [3]. Data grafik yang ditayangkan oleh KataData tahun 2017 juga menyebutkan bahwa para konsumen online di Indonesia paling sering melakukan belanja online melalui platform-platfrom media sosial, salah satunya melalui Instagram [4].

Dengan peningkatan penggunanya, media sosial Instagram kini dimanfaatkan sebagai platform online untuk berjualan dan mengembangkan bisnis atau yang disebut sebagai social commerce. Dalam laporan yang diliris oleh 'PayPal' bersama 'Blackbox Reseacrh' berjudul "Asia Social Commerce Report 2018", menunjukkan bahwa Instagram menjadi media sosial media sosial yang paling banyak digunakan pengusaha di Indonesia untuk mempromosikan bisnisnya [5]. Instagram merupakan aplikasi berbagi konten, dengan visual sebagai unsur yang dominan. Instagram dalam hal ini membantu pelaku usaha online untuk menemukan, terhubung, dan berinteraksi dengan calon pembeli melalui fitur-fitur yang ada, seperti foto, video, maupun fitur-fitur bisnis lainnya. Berdasarkan laporan yang diliris oleh 'Dana Rebecca Designs' menunjukkan bahwa platform Instagram memiliki pengaruh yang sangat signifikan terhadap keputusan pembelian konsumen untuk produk fashion [6].

Menurut riset yang diprakarsai oleh 'We Are Social' dan 'Hootsuite', produk fashion mendominasi pasar online sebagai sektor perdagangan yang paling mendominasi transaksi online di Indonesia [2]. Fashion merupakan istilah yang akrab dalam kehidupan sehari-hari. Fashion sering kali diidentikkan dengan busana atau pakaian, namun sebenarnya yang dikatakan fashion adalah segala sesuatu yang sedang tren dalam masyarakat. Mengutip Featherstone (2001) dalam Trisnawati (2011), fashion terutama busana, merupakan sisi kehidupan masyarakat yang saat ini sedemikian penting sebagai salah satu indikator bagi muncul dan berkembangnya gaya hidup (life style) [7].

Pertumbuhan industri fashion di Indonesiapun semakin pesat. Hal tersebut dibuktikan dengan maraknya namanama merek produk fashion lokal baru yang hadir di tengah masyarakat. Namun, tidak semua merek produk fashion lokal tersebut dapat diterima ataupun bertahan di tengah masyarakat. Era digitalisasi saat ini, menuntut para pengusaha produk fashion lokal tersebut untuk mampu beradaptasi dan melakukan strategi pemasaran digital. Salah satunya dengan memanfaatkan media sosial Instagram sebagai media promosi online produknya. Diantara sekian banyak merek produk fashion lokal yang ada di Indonesia, 'Cotton Ink' adalah salah satu merek produk fashion 'ready to wear' lokal yang paling menonjol dan populer. 'Cotton Ink' memanfaatkan media sosial Instagram sebagai media promosi dalam proses pemasaran produknya. Keberhasilan 'Cotton Ink' dalam pemasaran digital, dibuktikan dengan kondisinya saat ini yang sudah memiliki beberapa toko offline, serta berhasil mendapatkan berbagai penghargaan seperti Most Favorite Brand di Brightspot Market, The Most Innovative Local Brand dalam CLEO Fashion Award 2010, Best Local Brand 2010 dan 2012 oleh Free Magz, Favorite Local Label oleh In Style Magazine Award 2012, dan eX Plaza Indonesia Most Favorite Local Brand 2014. Selain itu, pada tahun 2016, nama Carline Darjanto, selaku Co-Founder and Creative Director 'Cotton Ink', berhasil masuk ke dalam Forbes Asia 30 Under 302016 sebagai entrepreneur muda di Asia yang berusia di bawah 30 tahun yang sukses dalam kategori retail and e-commerce [8]. Selain itu, 'Cotton Ink' juga mampu melebarkan bisnisnya dengan memiliki tiga label turunan, yakni 'Cotton Ink Studio', 'Cotton Ink Archipelago', dan 'Cotton Ink Mini' untuk menyasar segmentasi target market yang lebih luas [9].

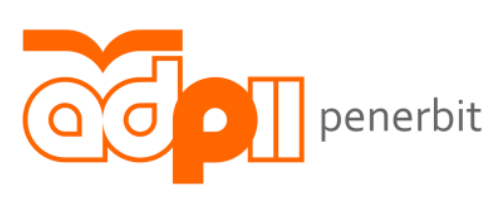

Penerbit Aliansi Desainer Produk Industri Indonesia 
Tak hanya berhasil dalam bidang promosinya saja, namun hal yang tak kalah penting dalam menarik perhatian konsumen adalah tampilan visualisasi fotografi yang disajikan dalam konten media sosial Instagram. Tantangan pemasaran digital adalah konsumen tidak dapat melihat, meraba, ataupun mencoba produk online secara langsung. Mereka hanya mengandalkan tampilan visualisasi foto serta kepercayaan terhadap merek dalam menilai kualitas produk yang pada akhirnya akan menentukan daya tarik, sikap, dan minat beli konsumen.

Melihat kesuksesan 'Cotton Ink' dalam proses pemasaran digitalnya, tentunya memiliki manfaat yang banyak jika diteliti dari kajian elemen visualisasi fotografi, serta mengetahui respon konsumen terhadap setiap elemen visual fotografi pada media promosi Instagram yang digunakan oleh 'Cotton Ink', agar dapat berkontrubusi bagi peningkatan pemasaran sebuah produk fashion.

\section{Metodologi}

Metode yang digunakan dalam penelitian ini adalah deskriptif kualitatif dengan pendekatan analisis konten. Metode deskriptif kualitatif merupakan suatu studi yang berupaya menjelaskan suatu fenomena atau variabel secara deskriptif dengan narasi yang jelas [10]. Sementara yang dimaksud dengan pendekatan analisis konten yaitu gambaran sistematis dari bentuk dan konten tulisan, ucapan, atau materi visual yang disajikan dalam tema, pola, dan menghitung kejadian dari kata-kata, frase, gambar, atau konsep [11].

Cara yang dilakukan adalah dengan menganalisis konten dari media promosi online Instagram yang digunakan oleh 'Cotton Ink'. Konten dari media sosial Instagram ini yang kemudian dijadikan sampel penelitian. Menurut Rose dalam Soewardikoen (2013), metode analisis konten didasari pada perhitungan frekuensi dari elemen visual tertentu yang terdapat dalam sampel gambar yang jelas, kemudian menganalisis hasil perhitungan [12]. Teknik analisis data dilakukan dengan analisis visual. Sampel yang telah dipilih dari media sosial Instagram 'Cotton Ink' akan dianalisis menggunakan teori umum mengenai fotografi dan gaya busana, kemudian dikaitkan dengan pemasaran. Selanjutnya, hasil dari pembahasan analisis tersebut akan dihubungkan dengan respon konsumen terhadap media promosi yang dilakukan oleh 'Cotton Ink'. Adapun teknik pengumpulan data dilakukan dengan cara observasi, focus group discussion (FGD), studi dokumentasi, dan studi pustaka.

\section{Diskusi}

\subsection{Analisis Konten Terhadap Promosi Instagram Cotton Ink}

Berdasarkan penjelasan mengenai analisis konten yang dikemukakan oleh Rose dalam Soewardikoen (2013), media sosial Instagram dari merek produk fashion lokal 'Cotton Ink' akan dianalisis dengan mengikuti dua tahap, yakni: (1) mengkategorikan unsur visual yang muncul dalam karya, dan (2) mengkategorikan unsurunsur berdasarkan ciri-cirinya.

Unsur visual yang muncul dalam media sosial Instagram 'Cotton Ink' dikategorikan berdasarkan observasi secara langsung pada akun media sosial Instagram yang diambil dari kurun waktu 2019-2020. Jumlah foto yang diunggah hingga tanggal 15 Oktober 2020 adalah 1.883 posts dan memiliki 22 kategori foto. Kategori foto tersebut diantaranya: (1) produk; (2) produk yang dikenakan oleh model; (3) produk yang dikenakan oleh owne; (4) produk yang dikenakan oleh influencers; (5) tim 'Cotton Ink'; (6) repost foto konsumen yang mengenakan produk; (7) kegiatan fashion show; (8) informasi sale product; (9) informasi kolaborasi merek; (10) informasi koleksi produk terbaru; (11) informasi konten majalah online edisi terbaru; (12) informasi promosi give away; (13) lokasi destinasi travelling dalam konten majalah online edisi terbaru; (14) behind the scene pemotretan; (15) toko fisik; (16) ucapan pada moment tertentu, seperti hari raya, valentine, dan sebagainya; (17) quotes; (18) meme; (19) zodiak; (20) penjelasan customer service; (21) tips dan trik berbusana; dan (22) 'Cotton Ink Men'.

Dari pengkategorian tersebut, kemudian dipilih berdasarkan frekuensi keseringan muncul dan memiliki jumlah foto terbanyak, serta terbatas pada kategori foto dengan tanpa adanya unsur teks tambahan pada visual. Terdapat lima kategori foto yang sesuai dengan pertimbangan tersebut, yaitu: (1) produk, (2) produk yang dikenakan oleh model, (3) produk yan dikenakan oleh influencers, (4) repost foto konsumen yang mengenakan

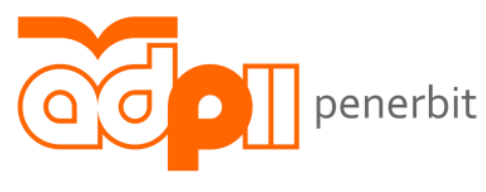

Penerbit Aliansi Desainer Produk Industri Indonesia 
produk, dan (5) kegiatan fashion show.

\subsection{Analisis Visual Terhadap Promosi Instagram 'Cotton Ink'}

Analisis visual dilakukan berdasarkan pendekatan teori umum tentang fotografi dan gaya busana, dengan hanya menggunakan beberapa elemen dari setiap unsur teori yang disesuaikan dengan keperluan dalam mengkaji visual foto. Adapun elemen visual foto yang dikaji meliputi tonal warna, jenis pengambilan gambar, arah pandang kamera, objek foto, latar, komposisi, aksesoris dan milineris, serta atribut busana. Foto yang digunakan sebagai sampel diambil berdasarkan pengelompokkan kategori foto yang telah dibahas pada analisis konten sebelumnya, yakni lima kategori foto. Dari setiap kategori foto tersebut, kemudian diambil 5-10 foto untuk dijadikan sampel. Sampel foto tersebut juga diambil berdasarkan jumlah like terbanyak yakni minimal berjumlah 1.000 likes. Berikut penjabaran analisis visual dari kelima kategori foto 'Cotton Ink' di Instagram.

Tabel 1. Analisis Visual Kategori Foto Produk

\begin{tabular}{|c|c|c|c|c|c|c|}
\hline \multicolumn{7}{|c|}{ Analisis Visual Foto Produk } \\
\hline Tonal Warna & Shot Type & Objek Foto & Latar & Komposisi & $\begin{array}{l}\text { Aksesoris } \\
\text { \& Milineris }\end{array}$ & Atribut Busana \\
\hline $\begin{array}{l}\text { Berbeda- } \\
\text { beda: warna- } \\
\text { warna cerah. } \\
\text { Pantone } \\
\text { color nuansa: } \\
\text { warm dan } \\
\text { naturals. }\end{array}$ & $\begin{array}{l}\text { Close up dan } \\
\text { medium shot. }\end{array}$ & $\begin{array}{l}\text { Produk pakaian } \\
\text { yang dilipat, di- } \\
\text { gantung, dan } \\
\text { disandingkan } \\
\text { dengan produk } \\
\text { lain/aksesoris. }\end{array}$ & Indoor & $\begin{array}{l}\text { Seimbang } \\
\text { dan rule of } \\
\text { third. }\end{array}$ & $\begin{array}{l}\text { Kacamata, } \\
\text { kosmetik, } \\
\text { dompet, tas, } \\
\text { sepatu, gelang, } \\
\text { hanger, dan } \\
\text { tiang hanger. }\end{array}$ & $\begin{array}{l}\text { Pakaian atasan, } \\
\text { celana panjang, } \\
\text { rok, dress. }\end{array}$ \\
\hline
\end{tabular}

Pada tabel kategori foto produk di atas, tonal warna yang ditampilkan bernuansa warm dan naturals. Menurut Dameria (2007), nuansa warm bersifat menerbarkan energi, menghangatkan, memancarkan keceriaan dan memberikan kenyamanan. Sementara nuansa naturals berkesan klasik, sederhana, dan trendy [13]. Jenis pengambilan gambar pada foto hampir seimbang antara close up dan medium shot. Objek foto yang disukai konsumen adalah visual produk pakaian yang ditampilkan dengan berbagai cara yakni secara dilipat, digantung, dan disandingkan dengan produk lainnya atau aksesoris pendukung. Untuk latar belakang dalam foto, konsumen cenderung menyukai foto dengan latar indoor, dengan komposisi foto seimbang dan rule of third.

Aksesoris dan milineris yang digunakan dalam menampilkan foto produk diantaranya ada gelang, kacamata, kosmetik, dompet, tas, dan sepatu, yang disandingkan dengan produk 'Cotton Ink' sebagai saran 'mix and match' pelengkap busana. Selain itu, ada juga hanger dan tiang hanger yang digunakan sebagai aksesoris pendukung untuk menampilkan visual foto produk dengan cara digantung. Untuk atribut busana yang disukai oleh konsumen pada merek 'Cotton Ink' cenderung bervariasi, mulai dari pakaian atasan, bawahan rok, celana panjang, hingga dress.

Tabel 2. Analisis Visual Kategori Foto Produk Yang Dikenakan Oleh Model

\begin{tabular}{|c|c|c|c|c|c|c|c|}
\hline \multicolumn{8}{|c|}{ Analisis Visual Foto Produk Yang Dikenakan Oleh Model } \\
\hline Tonal Warna & Shot Type & $\begin{array}{c}\text { Arah Pandang } \\
\text { Kamera }\end{array}$ & $\begin{array}{l}\text { Objek } \\
\text { Foto }\end{array}$ & Latar & Komposisi & $\begin{array}{l}\text { Aksesoris } \\
\text { \& Milineris }\end{array}$ & $\begin{array}{l}\text { Atribut } \\
\text { Busana }\end{array}$ \\
\hline $\begin{array}{l}\text { Berbeda- } \\
\text { beda: warna- } \\
\text { warna cerah. } \\
\text { Pantone color } \\
\text { nuansa: warm } \\
\text { dan naturals. }\end{array}$ & $\begin{array}{l}\text { Medium } \\
\text { shot dan } \\
\text { wide shot. }\end{array}$ & $\begin{array}{l}\text { Tampak depan } \\
\text { dan samping. }\end{array}$ & $\begin{array}{l}\text { Model } \\
\text { asing }\end{array}$ & Indoor & Seimbang & $\begin{array}{l}\text { Sepatu, } \\
\text { sendal, } \\
\text { anting, } \\
\text { topi, jilbab. }\end{array}$ & $\begin{array}{l}\text { Pakaian } \\
\text { atasan, celana } \\
\text { panjang, } \\
\text { kulot, rok, } \\
\text { dress, outer } \\
\text { wear. }\end{array}$ \\
\hline
\end{tabular}

Pada tabel kategori foto produk yang dikenakan oleh model, tonal warna bernuansa warm dan naturals. Sama

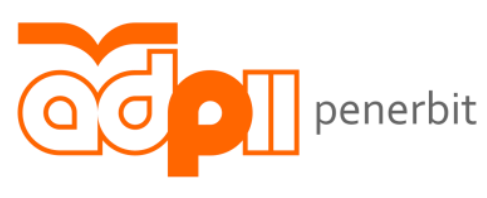

Penerbit Aliansi Desainer Produk Industri Indonesia 
seperti pada kategori foto produk sebelumnya, nuansa warm dan naturals dari pantone color pada kategori foto ini bersifat memberikan energi, kehangatan, kenyamanan, serta memancarkan keceriaan [13]. Sementara nuansa naturals bersifat klasik, sederhana, namun tetap trendy [13]. Jenis pengambilan gambar pada foto dilakukan secara medium shot dan wide shot. Foto produk yang dikenakan oleh model pada media Instagram tersebut memberikan arah pandang kamera dari tampak depan dan tampak samping dalam memperlihatkan produk. Objek foto yang disukai oleh konsumen untuk kategori foto ini adalah model wanita dengan paras asing. Untuk background pada foto, konsumen cenderung menyukai foto dengan latar indoor. Sementara dari segi komposisi pengambilan foto, menggunakan komposisi seimbang dan rule of third.

Aksesoris dan milineris yang dipakai oleh model pada kategori foto ini meliputi anting; jilbab (scarf); topi; sepatu jenis sneakers dan strappy heels; dan sendal sebagai pelengkap busana. Atribut busana yang disukai oleh konsumen pada kategori foto ini adalah pakaian atasan, bawahan rok, celana panjang, celana kulot, dress, dan outer wear.

Tabel 3. Analisis Visual Kategori Foto Produk Yang Dikenakan Oleh Influencers

\begin{tabular}{|c|c|c|c|c|c|c|}
\hline \multicolumn{7}{|c|}{ Analisis Visual Foto Produk Yang Dikenakan Oleh Influencers } \\
\hline Tonal Warna & Shot Type & Objek Foto & Latar & Komposisi & $\begin{array}{l}\text { Aksesoris } \\
\text { \& Milineris }\end{array}$ & Atribut Busana \\
\hline $\begin{array}{l}\text { Berbeda- } \\
\text { beda: warna } \\
\text { cerah. } \\
\text { Pantone color } \\
\text { nuansa: warm } \\
\text { dan naturals. }\end{array}$ & Wide shot & $\begin{array}{l}\text { Micro, macro, } \\
\text { dan mega } \\
\text { influencers. }\end{array}$ & Outdoor & $\begin{array}{l}\text { Seimbang } \\
\text { dan rule of } \\
\text { third. }\end{array}$ & $\begin{array}{l}\text { Kacamata, jam } \\
\text { tangan, jilbab, } \\
\text { tas, sepatu, } \\
\text { cincin, kalung, } \\
\text { gelang. }\end{array}$ & $\begin{array}{l}\text { Pakaian atasan, } \\
\text { celana panjang, } \\
\text { rok, outer } \\
\text { wear. }\end{array}$ \\
\hline
\end{tabular}

Berdasarkan tabel di atas, tonal warna yang ditampilkan pada kategori foto produk yang dikenakan oleh influencers bervariasi tergantung dari para influencers tersebut. Kebanyakan mereka menampilkan foto dengan warna-warna cerah. Pantone color pada kategori foto ini juga bernuasa warm dan naturals. Seperti yang telah dijabarkan sebelumnya bahwa menurut Dameria (2007), nuansa warna ini mampu memberikan kesan psikologis yang hangat, ceria, akrab, serta trendy [13]. Jenis pengambilan gambar pada foto sebagian besar dilakukan secara wide shot, dengan pengaturan komposisi secara seimbang dan rule of third. Tiga jenis kategori influencers yakni micro, macro, dan mega influencers menjadi objek foto yang menampilkan produk 'Cotton Ink'. Kategori tersebut diketahui dengan mengunjungi akun media sosial Instagram para influencers yang di-tag oleh 'Cotton Ink' dalam caption di setiap unggahan foto. Latar belakang pada foto yang paling banyak disukai oleh konsumen untuk kategori foto ini adalah latar outdoor.

Atribut busana merek 'Cotton Ink' yang dikenakan oleh para influencers tersebut dan paling banyak menarik perhatian konsumen adalah pakaian atasan, bawahan rok, celana panjang, serta outer wear. Aksesoris yang dipakai oleh para influencers sebagai pelengkap busana juga sangat beragam, diantaranya ada perhiasan berupa kalung, cincin, dan gelang. Sementara milineris yang dipakai meliputi kacamata; jam tangan; tas dalam berbagai model seperti envelope bag, bucket bag, shoulder bag, hobo bag, dan waist bag; serta berbagai jenis sepatu seperti sneakers, boots, slip on, flat shoes, flats sandals, slingback heels, dan stiletto high heels. Adapun jilbab dengan jenis pashmina juga digunakan oleh influencers yang berhijab.

Tabel 4. Analisis Visual Kategori Foto Konsumen Yang Mengenakan Produk

\begin{tabular}{|c|c|c|c|c|c|}
\hline \multicolumn{7}{|c|}{ Analisis Visual Foto Konsumen Yang Mengenakan Produk } \\
\hline Tonal Warna & Shot Type & Latar & Komposisi & $\begin{array}{c}\text { Aksesoris \& } \\
\text { Milineris }\end{array}$ & Atribut Busana \\
\hline
\end{tabular}


Jurnal Desain Indonesia Vol. 03 no. 01 - Aliansi Desainer Produk Industri Indonesia

\begin{tabular}{|l|l|l|l|l|l|}
\hline $\begin{array}{l}\text { Berbeda-beda: warna } \\
\text { cerah. }\end{array}$ & Wide shot & $\begin{array}{l}\text { Indoor dan } \\
\text { outdoor } \\
\text { Pantone color nuansa: } \\
\text { warm dan earthy. }\end{array}$ & Rule of third. & $\begin{array}{l}\text { Kacamata, tas, } \\
\text { sepatu, jilbab, } \\
\text { gelang. }\end{array}$ & Pakaian atasan \\
\hline
\end{tabular}

Pada foto konsumen yang memakai produk, tonal warna pada foto kategori ini juga bervariasi dengan warnawarna cerah dan pantone color yang bernuansa warm, naturals, dan earthy. Menurut Demeria (2007), secara psikologis pantone color pada kategori foto ini bersifat memberikan energi, kehangatan, kenyamanan, serta memancarkan keceriaan [13]. Sementara nuansa naturals bersifat klasik, sederhana, namun tetap trendy. Nuansa earthy juga menunjukkan kesan hangat, natural, elegan dan juga perasaan lembut. Selain itu, kategori earthy tone menjadi warna yang populer dalam dunia fashion di tahun 2020 ini [14]. Jenis pengambilan gambar yang digunakan pada foto juga sebagian besar dilakukan secara wide shot dan komposisi rule of third. Untuk latar pada kategori foto ini diambil di indoor dan outdoor.

Aksesoris dan milineris yang dikenakan oleh para konsumen sangat beragam, meliputi gelang; jilbab; kacamata hitam; jam tangan; tas jenis shoulder bag, hand bag, dan bucket bag; serta sandal dan sepatu mulai dari jenis sneakers, canvas shoes, hingga oxford shoes. Jenis atribut busana merek 'Cotton Ink' yang disukai oleh konsumen pada kategori foto ini adalah pakaian atasan, terutama untuk kategori jenis print shirt.

Tabel 5. Analisis Visual Kategori Foto Kegiatan Fashion Show

\begin{tabular}{|l|c|c|}
\hline \multicolumn{2}{|c|}{ Analisis Visual Foto Kegiatan Fashion Show } \\
\hline \multicolumn{1}{|c|}{ Tonal Warna } & Shot Type & Komposisi \\
\hline $\begin{array}{l}\text { Oranye. } \\
\text { Pantone color nuansa: warm dan naturals. }\end{array}$ & Wide shot \\
\hline
\end{tabular}

Pada kategori foto kegiatan fashion show, kebanyakan foto memiliki tonal warna oranye dengan pantone color bernuansa warm dan naturals. Hal tersebut karena pengaruh penataan cahaya (lighting) pada saat acara berlangsung. Secara psikologis, pantone color tersebut juga memberikan kesan penuh energi, hangat, nyaman, dan ceria. Selain itu penggunaan nuansa naturals memberikan kesan klasik, simple, dan trendy [13]. Jenis pengambilan gambar pada foto sebagian besar dilakukan dengan cara wide shot dengan menampilkan suasana kegiatan fashion show yang sedang berlangsung, serta komposisi foto yang seimbang.

\subsection{Persepsi Konsumen Terhadap Elemen Visual pada Promosi Instagram 'Cotton Ink'}

Pada penelitian ini telah dilakukan focus group discussion (FGD) dengan 9 orang responden yang sesuai dengan kriteria segmentasi konsumen (target market) 'Cotton Ink' yakni wanita berusia 20-30 tahun, bertempat tinggal di Bandung, dan merupakan pengguna aktif Instagram. Teknik pemilihan responden didasarkan atas sampel bertujuan (purposive sampling) agar dapat mewakili subjek konsumen 'Cotton Ink'.

Respon konsumen terhadap visual foto 'Cotton Ink' pada media sosial Instagram sangat ditentukan oleh elemen visual dan gaya busana yang dilihatnya. Elemen visual dan gaya busana tersebut telah memberikan dampak yang positif dalam menumbuhkan ketertarikan visual dan rencana konsumen untuk membeli produk 'Cotton Ink'. Hal ini menunjukkan bahwa pemenuhan elemen visual fotografi dan gaya busana pada media promosi Instagram terbukti dapat meningkatkan penjualan produk. Adapun beberapa bukti tentang respon konsumen terhadap elemen visual fotografi 'Cotton Ink' akan dijabarkan berikut ini.

1. Konsumen memiliki respon yang positif terhadap visual foto 'Cotton Ink' pada media sosial Instagram dilihat dari elemen tonal warna yang sebagian besar cenderung memberikan kesan simple, casual, chic, modern, comfortable, youthful, terlihat mahal, dan kekinian. Adapun respon konsumen terhadap kategori foto kegiatan fashion show cenderung ke arah high fashion, luxury, dan elegant. Kesan-kesan yang terbentuk ketika konsumen melihat elemen visual tonal warna ini, dapat memberikan daya tarik visual yang mempengaruhi ketertarikan untuk membeli produk.

2. Dilihat dari jenis pengambilan gambar, konsumen menyukai tipe close up (gambaran detail), medium

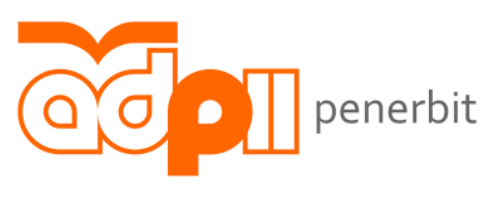

Penerbit Aliansi Desainer Produk Industri Indonesia 
shot (gambaran sedang), dan wide shot (gambaran menyeluruh).

3. Respon konsumen terhadap visual foto produk 'Cotton Ink' di media sosial Instagram cenderung menyukai arah pandang kamera dari tampak depan dan samping. Hal tersebut karena terlihat menarik dan dianggap dapat memberikan gambaran penggunaan produk dari sisi inti.

4. Dilihat dari elemen objek foto Instagram, untuk kategori visual foto produk, konsumen lebih menyukai tampilan visual foto pakaian yang digantung karena dapat memberikan gambaran produk yang lebih jelas. Sementara untuk kategori visual foto produk yang dikenakan oleh model, konsumen menyukai penggunaan model lokal dan asing. Hal tersebut karena dari segi estetika dan citra brand penggunaan model asing yang cantik dengan tubuh yang proposionlal, tinggi, berhidung mancung, dan berkulit putih dianggap menarik secara visual, serta mampu memberikan kesan professional. Sedangkan penggunaan model lokal dianggap mampu memberikan gambaran yang lebih nyata karena dianggap memiliki kondisi fisik yang sesuai dengan konsumen. Dengan kata lain, penggunaan model lokal dan asing, saling melengkapi dalam menjalankan fungsinya sebagai bagian dari strategi promosi untuk mempengaruhi sikap dan minat beli konsumen terhadap produk. Selain itu, untuk kategori visual foto yang dikenakan oleh influencers, konsumen cenderung menyukai kategori micro, macro, dan mega influencers dengan tampilan foto OOTD (outfit of the day) yang menarik.

5. Dilihat dari elemen latar, konsumen cenderung menyukai foto dengan latar indoor dan outdoor. Mereka menilai dengan penggunaan latar indoor, visual produk yang menjadi objek foto terlihat lebih jelas dan fokus. Sementara dengan penggunaan latar outdoor, konsumen mendapat gambaran tempat dan waktu yang sesuai dalam menggunakan produk, sehingga menjadi referensi dalam berbusana.

6. Respon konsumen terhadap elemen komposisi, mereka menyukai komposisi seimbang dan rule of third. Secara estetika, komposisi rule of third terlihat menarik dan tidak kaku. Sementara komposisi seimbang, mampu memberikan gambaran tentang produk secara lebih jelas dan fokus.

7. Konsumen cenderung menyukai busana yang dipadukan dengan aksesoris dan milineris karena terlihat lebih menarik dan dapat memberikan referensi dalam berbusana.

8. Untuk atribut busana yang disukai konsumen cenderung memilih pakaian atasan, bawahan celana panjang, rok, dress, dan outer wear. Hal tersebut karena jenis-jenis pakaian tersebut sering digunakan dalam keseharian konsumen.

\section{Kesimpulan}

Hasil penelitian ini menunjukkan bahwa visualisasi fotografi produk fashion lokal merek 'Cotton Ink' pada media sosial Instagram dapat meningkatkan penjualan produk. Visual foto 'Cotton Ink' pada media sosial Instagram tersebut telah memenuhi elemen visual fotografi, serta mendapat respon yang positif dari konsumen. Adapun elemen visualisasi fotografi yang dapat meningkatkan penjualan produk tersebut diantaranya: (1) tonal warna yang digunakan memiliki nuansa pantone color warm dan naturals, serta digunakan konsisten pada setiap unggahan foto di galeri Instagram; (2) jenis pengambilan gambar dilakukan secara wide shot, medium shot, dan close up; (3) arah pandang kamera yang digunakan yaitu tampak depan dan samping; (4) objek foto yang disukai yaitu foto produk yang digantung, dilipat, dan disandingkan dengan produk lain, serta penggunaan model lokal, model asing, dan influencers yang termasuk ke dalam kategori micro, macro, dan mega influencers; (5) latar yang digunakan yaitu latar indoor dan outdoor; (6) komposisi foto yang digunakan yaitu komposisi seimbang dan rule of third; (7) penggunaan aksesoris dan milineris dalam visual foto memberikan dampak positif yang disukai oleh konsumen; dan (8) jenis atribut busana seperti pakaian atasan, bawahan celana, rok, dress, dan outer wear merupakan jenis busana yang paling banyak disukai oleh konsumen. 'Cotton Ink' terbukti menggunakan elemen visual fotografi secara menarik dan lengkap, sehingga membuat konsumen tertarik dan dapat meningkatkan penjualan produk.

Sementara itu, respon positif konsumen terhadap elemen visual foto 'Cotton Ink' diantaranya: (1) penggunaan tonal warna memberikan respon konsumen bahwa melalui tonal warna ini dapat memberikan tampilan yang simple, casual, chic, modern, elegant, comfortable, youthful, terlihat mahal, dan kekinian; (2) jenis pengambilan gambar yang disukai adalah wide shot, medium shot, dan close up; (3) arah pandang kamera yang disukai adalah tampak depan dan tampak samping; (4) objek foto yang disukai yaitu foto produk yang digantung, penggunaan model lokal dan model asing, serta influencers yang termasuk ke dalam kategori micro,

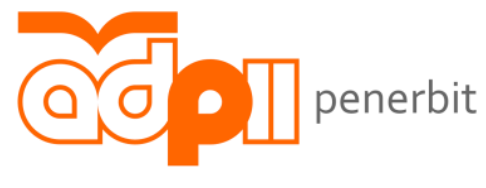

Penerbit Aliansi Desainer Produk Industri Indonesia 
macro, dan mega influencers; (5) penggunaan latar pada visual foto yang disukai konsumen adalah latar indoor dan outdoor; (6) jenis komposisi foto yang disukai oleh konsumen adalah komposisi seimbang dan rule of third; (7) penggunaan aksesoris dan milineris pada tampilan produk dinilai menarik dan disukai oleh konsumen; dan (8) jenis atribut busana yang lebih banyak disukai oleh konsumen adalah jenis busana pakaian atasan, bawahan celana, rok, dress, dan outer wear.

Dari kesimpulan yang telah dijabarkan di atas, membuktikan bahwa terdapat hubungan yang signifikan antara pemanfaatan teori visualisasi fotografi secara penuh dengan praktik pemasaran, serta terbentuknya respon konsumen yang positif. Hal tersebut menunjukkan bahwa dengan memanfaatkan media sosial Instagram yang memenuhi elemen visualisasi fotografi sebagai strategi pemasaran dig [1]ital produk fashion di era rovolusi industri 4.0 saat ini, terbukti dapat menimbulkan ketertarikan visual akan produk di benak konsumen, sehingga dapat meningkatkan penjualan produk.

\section{Referensi}

[1] D. J. Priansa, Komunikasi Pemasaran Terpadu Pada Era Media Sosial, Bandung: CV Pustaka Setia, 2017, p. 358.

[2] B. Ramadhan, "Data Internet di Indonesia dan Perilakunya Tahun 2020," 16 Februari 2020. [Online]. Available: https://teknoia.com/data-internet-di-indonesia-dan-perilakunya-880c7bc7cd19. [Accessed 10 Oktober 2020].

[3] M. Iman, "Pengguna Instagram di Indonesia Didominasi Wanita dan Generasi Milenial," 14 Juni 2020. [Online]. Available: https://www.goodnewsfromindonesia.id/2020/06/14/pengguna-instagram-diindonesia-didominasi-wanita-dan-generasi-milenial. [Accessed 10 Oktober 2020].

[4] iMarketplogy, "Apa yang Diungkapkan Data Tentang Pasar Online Indonesia dan Global?," 19 Mei 2020. [Online]. Available: https://marketingcraft.getcraft.com/id-articles/apa-yang-diungkapkan-data-tentangpasar-online-indonesia-dan-global. [Accessed 10 Oktober 2020].

[5] M. Nabila, "E-Commerce vs Social Commerce: Adu Kemudahan Berbelanja Online," 16 Agustus 2019. [Online]. Available: https://dailysocial.id/post/e-commerce-vs-social-commerce-adu-kemudahanberbelanja-online. [Accessed 8 Oktober 2020].

[6] D. Wulandari, "Seberapa Besar Instagram Mempengaruhi Pembelian Produk Fashion?," 21 Agustus 2017. [Online]. Available: https://mix.co.id/marcomm/brand-insight/research/seberapa-besar-instagrammempengaruhi-pembelian-produk-fashion/. [Accessed 8 Oktober 2020].

[7] T. Y. Trisnawati, "Fashion Sebagai Bentuk Ekspresi Diri dalam Komunikasi," Jurnal The Messenger, vol. III, Juli 2011.

[8] "Carline Darjanto Sukses di Industri Fesyen dengan Cotton Ink," 15 April 2019. [Online]. Available: https://www.kenangan.com/ceritainspirasi/carline-darjanto-sukses-di-industri-fesyen-dengan-cotton-ink. [Accessed 8 Oktober 2020].

[9] N. Salma, "Cotton Ink Pilih 4 Figur Wanita untuk Wakili Usia Segmen Pasar," 4 September 2018. [Online]. Available: https://swa.co.id/swa/trends/cottonink-pilih-4-figur-wanita-untuk-wakili-usia-segmen-pasar. [Accessed 10 Oktober 2020].

[10] Sugiyono, Memahami Penelitian Kualitatif, Bandung: CV Alfabeta, 2012.

[11] Martin B. Hanington B., Universal Methods of Design: 100 Ways to Research Complex Problems, Develop Innovative Ideas, and Design Effective Solutions, Beverly: Rockport Publishers, 2012.

[12] D. W. Soewardikoen, Metodologi Penelitian Visual dari Seminar ke Tugas Akhir, Bandung: CV Dinamika Komunika, 2013.

[13] A. Dameria, Color Basic Panduan Dasar Warna Untuk Desainer dan Industri Grafika, Jakarta: Link \& Match Graphic, 2007.

[14] "Bakal Hits pada 2020, 3 Desainer Hadirkan Koleksi Warna Earth Tone," 3 November 2019. [Online]. Available: https://www.jawapos.com/lifestyle/03/11/2019/bakal-hits-pada-2020-3-desainer-hadirkankoleksi-warna-earth-tone/. [Accessed 16 November 2020].

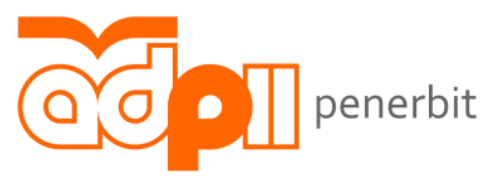

Penerbit Aliansi Desainer Produk Industri Indonesia 